\title{
ANALYSIS OF PHYSICAL CHARACTERISTICS OF BAMBOO
}

\section{FABRICS}

\author{
Ajay Rathod ${ }^{1}$, Avinash Kolhatkar ${ }^{2}$ \\ ${ }^{I}$ Department of Textile Engineering, JDIET, Yavatmal, Maharastra, India \\ ${ }^{2}$ Department of Textile Engineering, JDIET, Yavatmal, Maharastra, India
}

\begin{abstract}
This paper presents a study on physical properties of bamboo \& bamboo-cotton(50:50) blended yarn fabrics which are commonly used for apparel production. Yarns of 4 different counts such as 20,24,30\&40Ne were used as warp \& Weft in bamboo \& bamboo-cotton blended yarn fabric. All fabrics were produced in plain weave with 50 ppi. Various test such as breaking strength, elongation, fabric weight, thickness and abrasion resistance have been carried out to study the performance of bamboo \& bamboo-cotton(50:50) blended yarn fabrics. The experimental result indicates that 100\% bamboo fabric exhibits higher breaking strength than bamboo-cotton (50:50) blended yarn fabric. Higher elongation values are noticed in the case of 100\% bamboo fabric than bamboo-cotton (50:50) blended yarn fabrics. It is also found that 100\% bamboo fabric exhibits higher tearing strength than bamboo-cotton (50:50) blended yarn fabric of similar specifications. The 100\% bamboo fabric exhibits higher thickness than bamboo-cotton (50:50) blended yarn fabric of similar specifications. The cover factor of bamboo-cotton (50:50) blended yarn fabric is higher than bamboo fabric. It is found that $100 \%$ bamboo fabric exhibits better performance than bamboocotton (50:50) blended yarn fabrics.
\end{abstract}

Keywords: Analysis, Bamboo, Strength, Plain Weave, Pick Density.

\section{INTRODUCTION}

Bamboo fibre has been used various application such as building and construction, decoration, slope maintenance and high performance composites for the past many years. Regenerated bamboo fibres have characteristics mechanical properties of superior tensile strength, excellent UV protection, antibacterial and biodegradable characteristics, high moisture absorption, softness, brightness and high flexibility under flexible and compressive loads. With its high moisture absorption capacity, breathability and fast drying behavior, regenerated bamboo cellulose fibre ensures excellent comfort in various applications. Currently regenerated bamboo fibre is used in intimate apparels, hygienic products and sanitary materials, nonwovens and home furnishings [1].

Bamboo textile products are having high demands in the market because of their anti bacterial nature, biodegradable properties, high moisture absorption capacity, softness and UV protective capability [2]. Bamboo has much to offer in its raw form. Its geographical range is wide spread and its uses are numerous. As a grass, it has a diverse network of growth patterns and can flourish in harsh climates. Nevertheless, many animal and plant species depend on bamboo [3].

At present, there are two ways to utilize bamboo in the textile industry. One is to produce natural fibre from bamboo by chemical and physical treatment. The other method is to spin the regenerated fibre after the bamboo is retted into bamboo pulp. Since the latter has similar processing method of viscose. There are some advantages to the development of bamboo fibre for textiles. First, bamboo fibres are an environmental friendly fibre extracted from bamboo, which is renewable, fast growing, degradable and does not occupy cultivated land [4].

Bamboo is an antibacterial; relatively smooth fibre with low pilling and wrinkling, as well as high moisture sweat absorption, due to the micro gaps in its profile. Bamboo fabrics require less dyestuff than cotton fabrics in order to be dyed to the level desired, as they absorb the dyestuff better and faster and show the colour better [5].

Life standard is nowdays getting higher. The demands of people in all areas are increasing as well as the requirements regarding new textile materials with new or improved properties which are important for the required higher comfort or industrial use [6]. One of the most important aspects of clothing is comfort. Properties like thermal resistance, air permeability, water vapour permeability and liquid water permeability are critical for the thermal comfort of a clothed body. Comfort plays a vital role in the selection of apparel [7].

The demands from fabrics have changed with developments in technology and the rising living standards. Now the requirement is not only style and durability but also clothing comfort which includes psychological, sensorial and thermophysiological comfort. It is evident that fibre type, yarn properties, fabric structure, finishing treatments and clothing conditions are the main factors affecting clothing comfort. Bamboo fibre is a regenerated cellulosic fibre produced from bamboo. The type of bamboo used for apparel is moso bamboo. Starchy pulp is produced from bamboo stems and leaves through a process of alkaline hydrolysis and multi 
phase bleaching. Further chemical processes produce bamboo fibre. They have got numerous unique properties like inherent anti-bacterial property [8].

With the growing demand for more comfortable, healthier and environmentally friendly products, efforts in research and development activities in the textile industry have focused on the utilization of renewable and biodegradable resources as well as environmentally sound manufacturing processes in textiles. In this respect, a new kind of regenerated fibres which are an alternative to conventional ones[9]. An important area of textile is healthcare and hygiene sector among other medical applications. The range of products includes both disposable and non disposable items such surgical gown, mask, surgical drape, towels, gloves baby diapers, sanitary napkins and so on used in hospitals. Bamboo fibre has an excellent property that makes it ideal for processing into textiles. It is highly water absorbent, able to take up three times of its weight of water. Bamboo fibre has natural effect of sterilization, moisture vapour transmission property and easy drying. Therefore, this fibre will not cause skin allergies and its application in sanitary materials such as baby diaper, absorbent pads and sanitary towels is found to increase [10]. Hence, in the present work an attempt has been made to study and analyze the properties of $100 \%$ bamboo \& bamboo - cotton (50:50) blended yarn fabrics.

\section{MATERIALS AND METHODS}

\subsection{Materials}

\subsubsection{Fibre Properties}

Table-1 Physical Properties of Bamboo Fibre

\begin{tabular}{|l|l|}
\hline \multicolumn{2}{|l|}{ Physical Properties of Bamboo Fibre } \\
\hline Strength (g/tex) & 34.3 \\
\hline Elongation (\%) & 16.0 \\
\hline Short Fibre Index (12.7mm) & 5.58 \\
\hline Uniformity Index (\%) & 92.7 \\
\hline UHML(mm) & 38.745 \\
\hline ML (mm) & 35.62 \\
\hline Moisture (\%) & 6.5 \\
\hline Micronaire & 4.0 \\
\hline
\end{tabular}

Table-1 shows physical properties of bamboo fibre. Strength (gm/tex), Elongation (\%), Short fibre index, Uniformity index, Moisture (\%) and Micronaire are 34.3, 16.0, 5.58, $92.7,6.5$ and 4.0 respectively.

\subsubsection{Production of $100 \%$ Bamboo \& Bamboo:}

\section{Cotton (50:50) Fabric}

Yarns of 20, 24, 30, 40Ne of $100 \%$ bamboo \& bamboocotton (50:50) blend were used as warp \& weft in plain fabric of 50 ppi \& 75 epi. These fabric samples were produced with following fabric specifications on sample weaving machine.
Table-2 Specifications of Fabric

\begin{tabular}{|l|l|l|l|l|}
\hline Material & Weave & PPI & EPI & $\begin{array}{l}\text { WP \& WF } \\
\text { Count }\end{array}$ \\
\hline $100 \%$ Bamboo & Plain & 50 & 75 & $20,24,30,40$ \\
\hline $\begin{array}{l}\text { Bamboo-Cotton } \\
(50: 50)\end{array}$ & Plain & 50 & 75 & $20,24,30,40$ \\
\hline
\end{tabular}

\subsection{Experimental Methods}

\subsubsection{Fibre Properties}

Fibre properties such as strength, elongation, micronaire and uniformity index and moisture \% etc. of bamboo are measured on Uster HVI SW 3.1.1.0 version.

\subsubsection{Yarn Properties}

Yarn properties such as strength and elongation are measured on Uster Tensorapid Tester (3 V 6.1) with gauge length- 20 inches, velocity of jaw $2000 \mathrm{~mm} / \mathrm{min}$. While unevenness, imperfection and hairiness were measured on IQ Qualicentre (version A 3.0.2) with 400 meter test length.

\subsubsection{Fabric Properties}

Physical properties of fabric such as fabric mass(ASTMD3776:2009), thickness(ASTM D1777:2007), tearing strength (ASTM D1424:2009), breaking strength (IS 19691985, R.A.2006), elongation (IS 1969-1985, R.A.2006), abrasion resistance (ASTM D4966-98, R.A.2007) etc were measured as per standards testing methods after conditioning the specimens at $65 \% \mathrm{RH}$ and $27+/-2^{\circ} \mathrm{C}$ for $24 \mathrm{Hrs}$.

\section{RESULTS AND ANALYSIS}

3.1 Physical Properties of Fabric (Plain Fabric- 50 ppi)

\subsubsection{Breaking Strength $(\mathrm{Kg})$}

Table 3.1: Breaking Strength

\begin{tabular}{|l|l|l|}
\hline Code & $\begin{array}{l}\text { Sample Particulars } \\
\text { PPI 50 }\end{array}$ & $\begin{array}{l}\text { Breaking } \\
\text { Strength }\end{array}$ \\
\hline A & $20 \mathrm{Ne} \mathrm{100 \%} \mathrm{Bamboo}$ & 18.12 \\
\hline C & $20 \mathrm{Ne} \mathrm{50:50 \%} \mathrm{Bamboo/Cotton}$ & 17.4 \\
\hline E & $24 \mathrm{Ne} \mathrm{100 \%} \mathrm{Bamboo}$ & 29.4 \\
\hline G & $24 \mathrm{Ne} \mathrm{50:50} \mathrm{Bamboo/Cotton}$ & 15.5 \\
\hline I & 30 Ne 100\% Bamboo & 21.9 \\
\hline K & 30 Ne 50:50\% Bamboo/Cotton & 15.4 \\
\hline M & $40 \mathrm{Ne} \mathrm{100 \%} \mathrm{Bamboo}$ & 30.95 \\
\hline O & $40 \mathrm{Ne} 50: 50$ Bamboo/Cotton & 21.5 \\
\hline
\end{tabular}




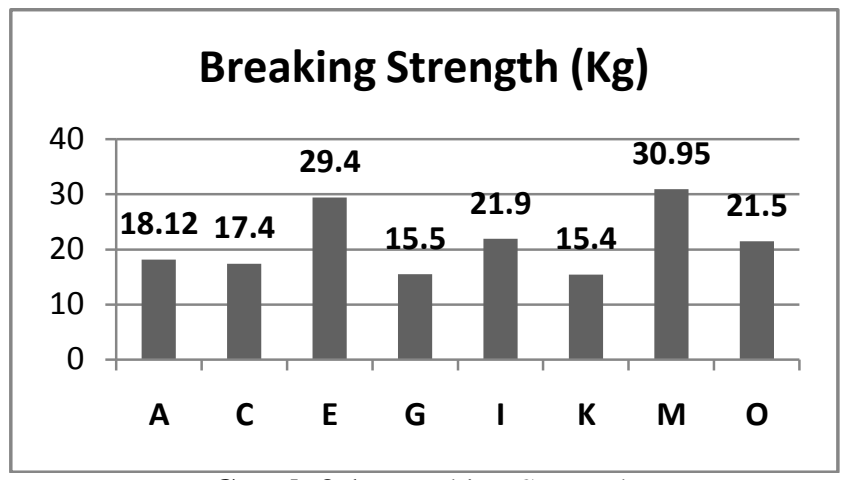

Graph 3.1: Breaking Strength

Table 3.1 \& Graph 3.1 show results of breaking strength of $100 \%$ bamboo \& bamboo-cotton (50:50) blended yarn fabrics. The experimental result shows that, bamboo fabric exhibits higher breaking strength than bamboo-cotton (50:50) blended yarn fabric. This result may be attributed to higher tenacity of bamboo fibre. The breaking strength is considerably higher for sample $\mathrm{M}$ compared with those for other samples.

\subsubsection{Elongation (\%)}

Table 3.2: Elongation $\%$

\begin{tabular}{|l|l|l|}
\hline Code & $\begin{array}{l}\text { Sample Particulars } \\
\text { PPI 50 }\end{array}$ & $\begin{array}{l}\text { Elongation } \\
(\boldsymbol{\%})\end{array}$ \\
\hline $\mathrm{A}$ & 20 Ne 100\% Bamboo & 28.03 \\
\hline $\mathrm{C}$ & 20 Ne 50:50\% Bamboo/Cotton & 24.37 \\
\hline $\mathrm{E}$ & $24 \mathrm{Ne} \mathrm{100 \%} \mathrm{Bamboo}$ & 36.96 \\
\hline $\mathrm{G}$ & 24 Ne 50:50 Bamboo/Cotton & 31.54 \\
\hline $\mathrm{I}$ & 30 Ne 100\% Bamboo & 23.37 \\
\hline $\mathrm{K}$ & 30 Ne 50:50\% Bamboo/Cotton & 23.76 \\
\hline $\mathrm{M}$ & $40 \mathrm{Ne} \mathrm{100 \%} \mathrm{Bamboo}$ & 27.12 \\
\hline $\mathrm{O}$ & $40 \mathrm{Ne} 50: 50 \mathrm{Bamboo} / \mathrm{Cotton}$ & 22.57 \\
\hline
\end{tabular}

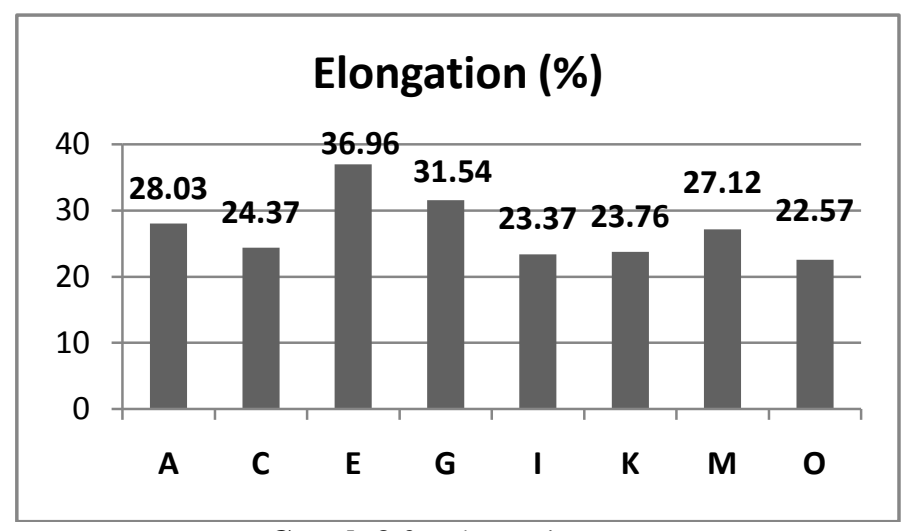

Graph 3.2: Elongation \%

Table 3.2 \& Graph 3.2 show results of elongation \% of $100 \%$ bamboo \& bamboo-cotton (50:50) blended yarn fabrics. The experimental result shows that, bamboo fabric exhibits higher elongation than bamboo-cotton (50:50) blended yarn fabric. This result may be attributed to higher elongation of bamboo fibre. From the results, it is observed that higher elongation values are noticed in the case of $100 \%$ bamboo fabric than bamboo-cotton (50:50) blended yarn fabrics.

\subsubsection{Fabric Weight $\left(\mathrm{gm} / \mathrm{m}^{2}\right)$}

Table 3.3: Fabric Weight

\begin{tabular}{|l|l|l|}
\hline Code & $\begin{array}{l}\text { Sample Particulars } \\
\text { PPI 50 }\end{array}$ & $\begin{array}{l}\text { Fabric } \\
\text { Weight }\end{array}$ \\
\hline $\mathrm{A}$ & 20 Ne 100\% Bamboo & 90.2 \\
\hline $\mathrm{C}$ & 20 Ne 50:50\% Bamboo/Cotton & 90.56 \\
\hline $\mathrm{E}$ & 24 Ne 100\% Bamboo & 91.5 \\
\hline $\mathrm{G}$ & 24 Ne 50:50 Bamboo/Cotton & 92 \\
\hline $\mathrm{I}$ & 30 Ne 100\% Bamboo & 91.1 \\
\hline $\mathrm{K}$ & 30 Ne 50:50\% Bamboo/Cotton & 90.3 \\
\hline $\mathrm{M}$ & $40 \mathrm{Ne} \mathrm{100 \%} \mathrm{Bamboo}$ & 90.8 \\
\hline $\mathrm{O}$ & $40 \mathrm{Ne} 50: 50$ Bamboo/Cotton & 92.35 \\
\hline
\end{tabular}

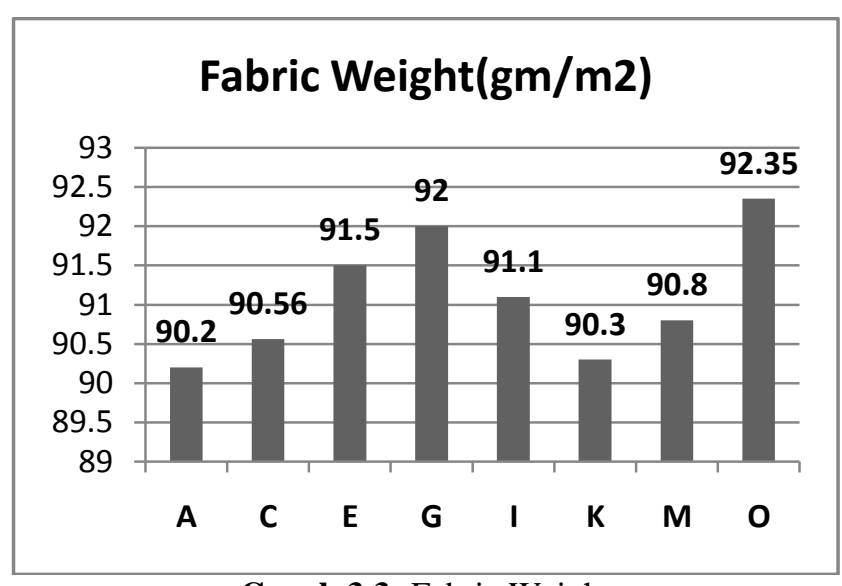

Graph 3.3: Fabric Weight

The results of fabric weight of $100 \%$ bamboo \& bamboocotton (50:50) blended yarn fabrics are shown in table $3.3 \&$ graph 3.3. The results indicate that fabric weight of bamboocotton (50:50) blended fabric is higher than $100 \%$ bamboo fabric. This may be due to difference in linear densities of fibres.

\subsubsection{Tearing Strength $(\mathrm{kg})$}

Table 3.4: Tearing Strength

\begin{tabular}{|l|l|l|}
\hline Code & $\begin{array}{l}\text { Sample Particulars } \\
\text { PPI 50 }\end{array}$ & $\begin{array}{l}\text { Tearing } \\
\text { Strength }\end{array}$ \\
\hline $\mathrm{A}$ & 20 Ne 100\% Bamboo & 46 \\
\hline $\mathrm{C}$ & $20 \mathrm{Ne}$ 50:50\% Bamboo/Cotton & 40 \\
\hline $\mathrm{E}$ & $24 \mathrm{Ne} \mathrm{100 \%} \mathrm{Bamboo}$ & 42.5 \\
\hline $\mathrm{G}$ & $24 \mathrm{Ne} \mathrm{50:50} \mathrm{Bamboo/Cotton}$ & 42. \\
\hline $\mathrm{I}$ & $30 \mathrm{Ne} \mathrm{100 \%} \mathrm{Bamboo}$ & 44.2 \\
\hline $\mathrm{K}$ & $30 \mathrm{Ne} \mathrm{50:50 \%} \mathrm{Bamboo/Cotton}$ & 43.2 \\
\hline $\mathrm{M}$ & $40 \mathrm{Ne} \mathrm{100 \%} \mathrm{Bamboo}$ & 40.01 \\
\hline $\mathrm{O}$ & $40 \mathrm{Ne} 50: 50 \mathrm{Bamboo} / \mathrm{Cotton}$ & 39.2 \\
\hline
\end{tabular}




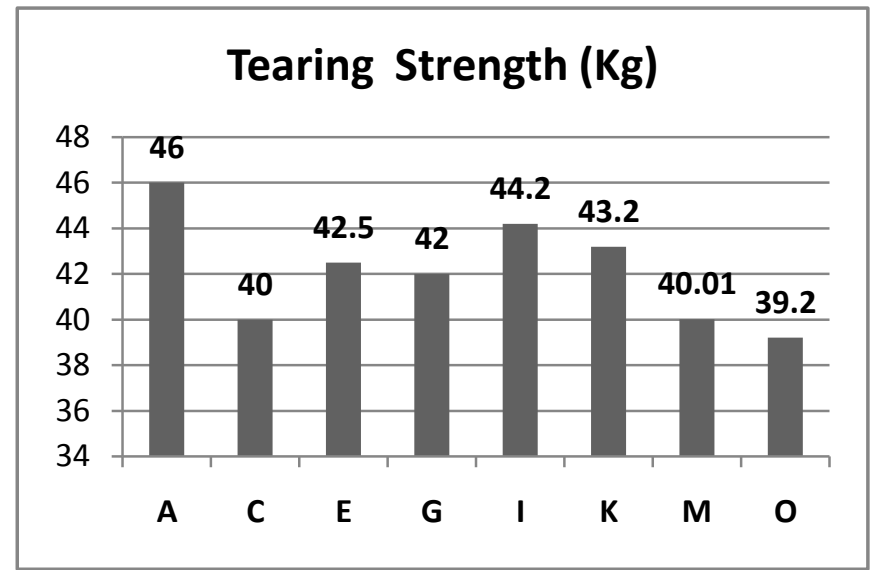

Graph 3.4: Tearing Strength

Table $3.4 \&$ graph 3.4 shows results of tearing strength of $100 \%$ bamboo \& bamboo-cotton (50:50) blended yarn fabrics. The experimental result shows that sample A has higher tearing strength when compared to all other samples. It is also found that $100 \%$ bamboo fabric exhibits higher tearing strength than bamboo-cotton (50:50) blended fabric of similar specifications.

\subsubsection{Cover Factor}

Table 3.5: Cover Factor

\begin{tabular}{|l|l|l|}
\hline Code & $\begin{array}{l}\text { Sample Particulars } \\
\text { PPI 50 }\end{array}$ & $\begin{array}{l}\text { Cover } \\
\text { Factor }\end{array}$ \\
\hline A & 20 Ne 100\% Bamboo & 19.92 \\
\hline C & 20 Ne 50:50\% Bamboo/Cotton & 21.25 \\
\hline E & 24 Ne 100\% Bamboo & 20.25 \\
\hline G & 24 Ne 50:50 Bamboo/Cotton & 21.00 \\
\hline I & 30 Ne 100\% Bamboo & 22.05 \\
\hline K & 30 Ne 50:50\% Bamboo/Cotton & 22.05 \\
\hline M & $40 \mathrm{Ne} \mathrm{100 \%} \mathrm{Bamboo}$ & 16.32 \\
\hline O & 40 Ne50:50 Bamboo/Cotton & 17.20 \\
\hline
\end{tabular}

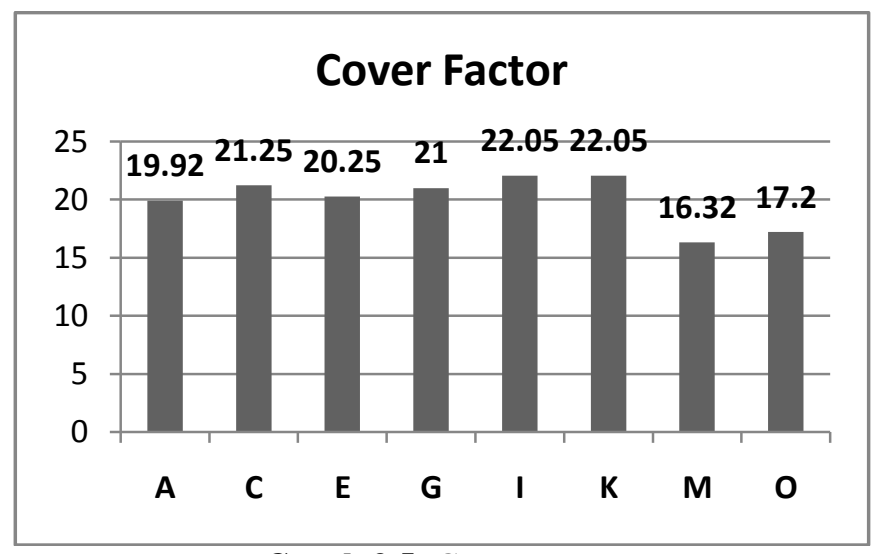

Graph 3.5: Cover Factor

Table $3.5 \&$ graph 3.5 illustrates the values of cover factor of $100 \%$ bamboo \& bamboo-cotton (50:50) blended yarn fabrics. The experimental results show that, bamboo-cotton (50:50) blended yarn fabrics exhibits better values of cover factor than bamboo fabric. This may be due to higher hairiness of bamboo-cotton (50:50) blended yarn.

\subsubsection{Thickness (mm)}

Table 3.6: Thickness

\begin{tabular}{|l|l|l|}
\hline Code & $\begin{array}{l}\text { Sample Particulars } \\
\text { PPI 50 }\end{array}$ & $\begin{array}{l}\text { Thickness } \\
(\mathbf{m m})\end{array}$ \\
\hline $\mathrm{A}$ & $20 \mathrm{Ne}$ 100\% Bamboo & 0.35 \\
\hline $\mathrm{C}$ & $20 \mathrm{Ne}$ 50:50\% Bamboo/Cotton & 0.34 \\
\hline $\mathrm{E}$ & $24 \mathrm{Ne} \mathrm{100 \%} \mathrm{Bamboo}$ & 0.36 \\
\hline $\mathrm{G}$ & $24 \mathrm{Ne} 50: 50$ Bamboo/Cotton & 0.36 \\
\hline $\mathrm{I}$ & $30 \mathrm{Ne}$ 100\% Bamboo & 0.36 \\
\hline $\mathrm{K}$ & $30 \mathrm{Ne}$ 50:50\% Bamboo/Cotton & 0.31 \\
\hline $\mathrm{M}$ & $40 \mathrm{Ne} \mathrm{100 \%} \mathrm{Bamboo}$ & 0.38 \\
\hline $\mathrm{O}$ & $40 \mathrm{Ne} 50: 50 \mathrm{Bamboo} /$ Cotton & 0.36 \\
\hline
\end{tabular}

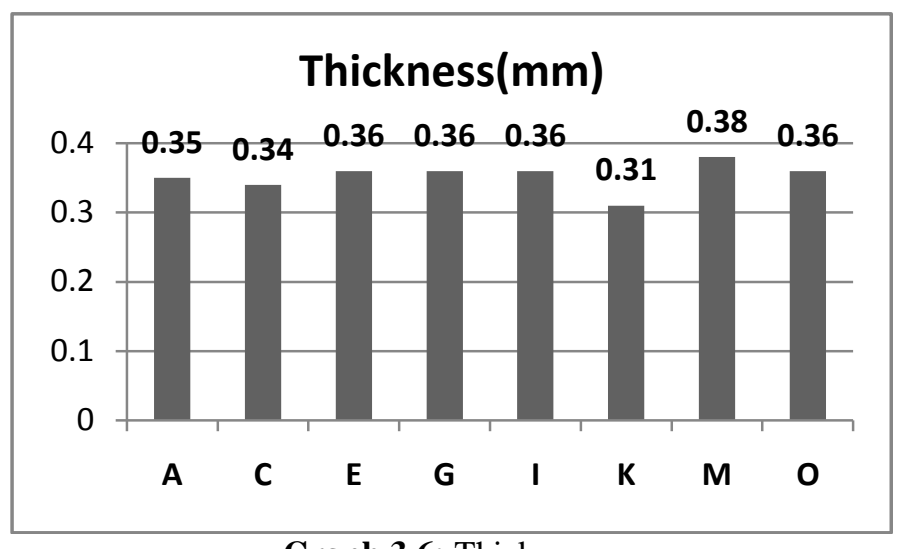

Graph 3.6: Thickness

Table 3.6 \& graph 3.6 shows results of thickness of $100 \%$ bamboo \& bamboo-cotton (50:50) blended yarn fabrics. It is found that $100 \%$ bamboo fabric exhibits higher thickness than bamboo-cotton (50:50) blended yarn fabric of similar specifications. This result may be attributed to higher hairiness of $100 \%$ bamboo yarn.

\subsubsection{Abrasion Resistance}

Table 3.7: Abrasion Resistance

\begin{tabular}{|l|l|l|}
\hline Code & $\begin{array}{l}\text { Sample Particulars } \\
\text { PPI 50 }\end{array}$ & $\begin{array}{l}\text { Abrasion } \\
\text { Resistance }\end{array}$ \\
\hline C & $20 \mathrm{Ne} \mathrm{50:50 \%} \mathrm{Bamboo/Cotton,}$ & 4 \\
\hline D & $20 \mathrm{Ne} \mathrm{100 \%} \mathrm{Bamboo}$ & 3 \\
\hline I & $30 \mathrm{Ne} \mathrm{100 \%} \mathrm{Bamboo}$ & 5 \\
\hline J & $30 \mathrm{Ne} \mathrm{50:50 \%} \mathrm{Bamboo/Cotton}$ & 3 \\
\hline K & $40 \mathrm{Ne} \mathrm{50:50 \%} \mathrm{Bamboo/Cotton}$ & 3 \\
\hline N & $40 \mathrm{Ne} \mathrm{100 \%} \mathrm{Bamboo}$ & 4 \\
\hline
\end{tabular}




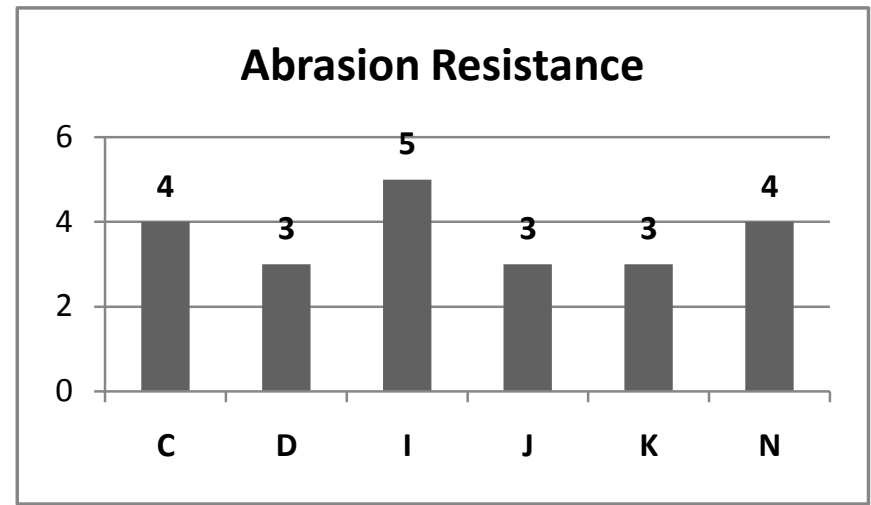

Graph 3.7: Abrasion Resistance

As shown in table-3.7 \& graph-3.7. The abrasion resistance of $100 \%$ bamboo \& (50:50) bamboo: cotton blended yarn fabric is $4,3,5,3,3$ and 4 respectively.

\section{CONCLUSIONS}

The physical characteristics of woven fabrics made from $100 \%$ bamboo \& bamboo-cotton (50:50) blended yarn have been analyzed.

Bamboo fabric exhibits higher breaking strength than bamboo-cotton (50:50) blended yarn fabric. Higher elongation values are noticed in the case of $100 \%$ bamboo fabric than bamboo-cotton (50:50) blended yarn fabrics. It is also found that $100 \%$ bamboo fabric exhibits higher tearing strength than bamboo-cotton (50:50) blended yarn fabric of similar specifications. The $100 \%$ bamboo fabric exhibits higher thickness than bamboo-cotton (50:50) blended yarn fabric of similar specifications. The cover factor of bamboocotton (50:50) blended yarn fabric is higher than bamboo fabric.

\section{REFERENCES}

[1]. G.K. Tyagi, S.Bhattacharaya \& G.Kherdekar, “ Comfort Behavior of Woven Bamboo-Cotton Ring and MJS Yarn Fabrics," Indian Journal of Fibre \& Textile Research, Vol.36, pp.47-52, March 2011.

[2]. Abhijit Majumdar, Samrat Mukhopadhayay, Ravindra Yadav \& Achintya Kumar Mondal, “ Properties of Ring Spun Yarns Made from Cotton and Regenerated Bamboo Fibre," Indian Journal of Fibre \& Textile Research, Vol.36, pp.18-23,March 2011.

[3]. Marilyn Waite, "Sustainable Textiles: The Role of Bamboo and a Comparison of Bamboo Textile Properties" Journal of Textile and Apparel Technology and Management, Vol.6, Issue 2, Fall 2009.

[4]. Wang Yueping, Wang Ge, Cheng Haitao, et.al "Structure of Bamboo fibre for Textile" Textile Research Journal, 80(4),pp.334-343, 2009.

[5]. Filiz Sekerden, "Effect of Fabric Weave and Weft Types on the Characteristics of Bamboo/Cotton Woven Fabric" Fibre \& Textiles in Eastern Europe, Vol.19, No. 6(89),PP.47-52, 2011.

[6]. Prakash Chidambaram \& Ramakrishnan Govindan, "Influence of Blend Ratio on Thermal Properties of Bamboo-
Cotton Blended Woven Fabric" Silpakorn U Science \& Technology Journal, Vol. 6(2), pp.49-55, 2012.

[7]. Prakash Chidambaram, Ramakrishana Govind \& Koushik Chadramouli Venkataraman, “ The Effect of Loop Length and Yarn Linear Density on the Thermal Properties of Bamboo Knitted Fabric" Autex Research Journal, Vol.11, No.4, pp.102-105,December 2011.

[8]. Sudipta S Mahish, A. K. Patra \& Rashmi Thakur, “ Functional Properties of Bamboo/Polyester Blended Knitted Apparel Fabrics" Indian Journal of Fibre \& Textile Research, Vol.37, pp.231-237, Sept.2012.

[9]. Nazan Erdumlu \& Bulent Ozipek, “ Investigation of Regenerated Bamboo Fibre and Yarn Characteristics", Fibre \& Textiles in Eastern Europe, Vol.16, No.4(69),PP.43-47, 2008.

[10]. O. L. Shanmugasundaram, R V M Gowda, "Development and Characterization of Bamboo and Organic Cotton Fibre Blended Baby Diapers" Indian Journal of Fibre \& Textile Research, Vol.35, pp.201-205, Sept.2010.

[11]. R.Perumalraj, V. Arun Kumar, M. Mohanraj and S. Boopathraj, "Moisture Management Properties of Polyester with Bamboo Biply Knitted Fabrics," Elixir International Journal, 53, pp-11690-11694, 2012.

[12]. Prakash Chidambaram, Ramakrishana Govind \& Koushik Chadramouli Venkataraman, " Study of Thermal Comfort Properties of Cotton/Regenerated Bamboo Knitted Fabrics" African Journal of Basic \& Applied Sciences, 4(2),pp.60-66, 2012. 